\title{
Equine sarcoid of the glans penis with bovine papillomavirus type 1 in a miniature horse (Falabella)
}

\author{
Kikumi OGIHARA ${ }^{1) \#, ~ A k i k a z u ~ I S H I H A R A ~}{ }^{2) \#}$, Makoto NAGAI ${ }^{3)}$, Kazutaka \\ YAMADA ${ }^{4)}$, Testuya MIZUTANI6), Mei HARAFUJI7), Hisanari NISHIO5) \\ and Hiroo MADARAME ${ }^{5) *}$
}

1)Laboratory of Pathology, School of Life and Environmental Science, Azabu University, Kanagawa 252-5201, Japan

2)Laboratory of Farm Animal Internal Medicine, School of Veterinary Medicine, Azabu University, Kanagawa 252-5201, Japan

3)Laboratory of Infectious Diseases, School of Veterinary Medicine, Azabu University, Kanagawa 252-5201, Japan

4)Laboratory of Clinical Diagnosis, School of Veterinary Medicine, Azabu University, Kanagawa 252-5201, Japan

5) Laboratory of Small Animal Clinics, Veterinary Teaching Hospital, Azabu University, Kanagawa 252-5201, Japan

6) Research and Education Center for Prevention of Global Infectious Diseases of Animal, Tokyo University of Agriculture and Technology, Tokyo 183-0054, Japan

${ }^{7)}$ Nasu Animal Kingdom, Tochigi 329-3223, Japan

J. Vet. Med. Sci.

83(6): 1016-1021, 2021

doi: 10.1292/jvms.21-0170

Received: 21 March 2021

Accepted: 19 April 2021

Advanced Epub:

28 April 2021
ABSTRACT. A 23-year-old Falabella gelding kept in Tochigi, Japan, for more than 20 years presented with a recurrent mass of the glans penis that was first noticed about a year earlier. Partial phallectomy was performed with no adjunctive therapy for local regrowth of the mass. The horse was euthanized 3 months after surgery for urinary retention due to suspected regrowth. The resected mass affected the genital and urethral mucosa of the glans penis, and was diagnosed as equine sarcoid by histopathology and identification of bovine papillomavirus (BPV) DNA. Phylogenetic analysis of the BPV genome of the sarcoid showed high sequence homology to BPV type 1 (BPV-1) from Hokkaido, Japan, suggesting a geographical relationship for BPV-1 in Japan. KEY WORDS: bovine papillomavirus, equine sarcoid, glans penis, mucosal sarcoid, phylogenetic analysis

Equine sarcoid is the most important and common papillomavirus (PV)-induced skin tumor in horses worldwide [14, 16, 21], and genomic studies of causative bovine papillomavirus (BPV) have been reported in many countries, including in Japan [29]. Although PVs are known to have a dual tropism for the skin and mucosa [1,29], there are few reported cases of mucosal sarcoid. Equine sarcoid of the oral and orbital mucosa has not been reported, although two cases involving the penile mucosa of the glans penis have been reported from Iran [10, 20]. This report provides a detailed morphological description of equine sarcoid involving the genital and urethral mucosa of the glans penis and the urethral process as well as a complete genomic sequence and phylogenetic analysis of BPV type 1 (BPV-1) in Japan.

A 23-year-old Falabella gelding that had been kept in the zoo of Tochigi prefecture for more than 20 years was referred to Azabu University for investigation and treatment of a mass of the glans penis, which had recurred twice in the previous year. Clinically, the first mass of the glans penis had grown over approximately 6 months after bleeding from the penile root, at which time the first resection was performed. The resected mass was histopathologically diagnosed as suppurative inflammation and degeneration/necrosis with formation of granulation tissue. Approximately 6 months later, the mass regrew and a second resection was performed. A third resection of the mass of the glans penis was performed at the Large Animal Veterinary Educational Center of Azabu University after a further 6 months. On physical examination, the mass of the glans penis was reddish, proud flesh-like, and partly covered with yellowish-white pus (Fig. 1). There were no abnormalities of the penile shaft, no preputial abnormalities, and no regional lymphadenopathy. Partial phallectomy was performed using William's technique, and no adjunctive therapy was administered to prevent local tumor regrowth. The horse was

*Correspondence to: Madarame, H.: madarame@azabu-u.ac.jp

\#These authors contributed equally to this work.

(C2021 The Japanese Society of Veterinary Science

This is an open-access article distributed under the terms of the Creative Commons Attribution Non-Commercial No Derivatives (by-nc-nd) License. (CC-BY-NC-ND 4.0: https://creativecommons.org/licenses/by-nc-nd/4.0/) 
euthanized 3 months after surgery for urinary retention due to suspected regrowth of the mass. Necropsy was not performed.

Fresh tissue samples were fixed in 10\% neutral buffered formalin, trimmed, embedded in paraffin wax, and processed routinely for histopathological examination. Four-micrometer-thick sections were stained with hematoxylin and eosin, and selected sections were stained with Azan trichrome. Additional sections were subjected to immunohistochemical analyses. The primary antibodies used are listed in Table 1. Labeled antigens were detected using a Histofine Simple Stain MAX PO (MULTI) kit (Nichirei Biosciences, Tokyo, Japan). Each antibody was visualized using 3-3'- diaminobenzidine (Nichirei Biosciences). The slides were counterstained with Mayer's hematoxylin.

For electron microscopy, tissue samples were cut into $1-\mathrm{mm}^{3}$ cubes, fixed in $2.5 \%$ glutaraldehyde, and post-fixed in $1 \%$ osmium tetroxide (Nisshin EM, Tokyo, Japan). The fixed specimens were then dehydrated with graded ethanol and embedded in epoxy resin (Quetol-812 set; Nisshin EM). Ultrathin sections were cut using an ultramicrotome (EM UC7; Leica Microsystems, Wetzlar, Germany), double-stained with uranyl acetate and lead citrate, and examined with a JEOL 1210 transmission electron microscope (JEOL, Tokyo, Japan) at $80 \mathrm{kV}$.

For detection of BPV, frozen tissue samples were minced with scissors, diluted 1:10 in phosphate-buffered saline, and homogenized for $20 \mathrm{sec}$ at $3,200 \mathrm{rpm}$ in the presence of three stainless steel beads $(\varphi 4 \mathrm{~mm})$ using a $\mu \mathrm{T}-12$ bead crusher (Taitec, Saitama, Japan), and centrifuged at 12,000 $g$ for $5 \mathrm{~min}$. Viral DNA was extracted from the supernatant using a QIAamp DNA Mini Kit (Qiagen, Hilden, Germany). Polymerase chain reaction (PCR) for detection of BPV DNA was performed based on three-step cycle conditions using GoTaq ${ }^{\circledR}$ G2 Hot Start Taq Polymerase (Promega, Madison, WI, USA) with the MY09-MY11 primer pair [13]. The PCR products were electrophoresed on 2\% agarose gel, stained with Midori Green Advance (Nippon Genetics, Tokyo, Japan), and visualized using a UV transilluminator.

To obtain the complete genome sequence of BPV from the equine tissue samples, long PCR was performed using PrimeSTAR GXL DNA polymerase (Takara Bio, Kusatsu, Japan) using three primer pairs: BPV1_ wholw_1, BPV1_whole_2, and BPV1_whole_3 [23]. A fragmented library was constructed from the PCR products generated using the Nextera XT kit (Illumina, San Diego, CA, USA). Samples were bar-coded using the Nextera XT index kit v2 (Illumina), and sequencing was performed on a MiSeq sequencer. FASTQ files created by the MiSeq Reporter (Illumina) were imported into the CLC Genomics Workbench 7.5.5 (CLC bio, Aarhus, Denmark). Contigs were created from trimmed reads using de novo assembly with default parameters in the CLC Genomics Workbench.

The complete genome sequence was deposited in the DDBJ/EMBL/ GenBank database under the accession number LC549663. Phylogenetic analysis was performed based on the complete genome nt sequence using the neighbor-joining method in MEGA7 [12]. The trees were

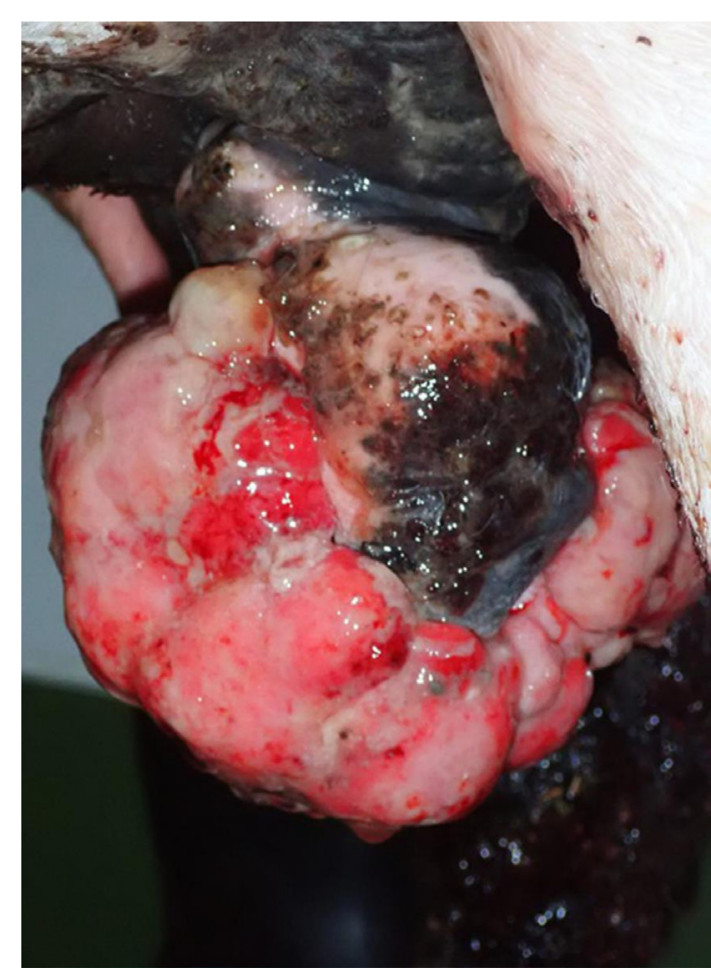

Fig. 1. Mass of the glans penis. Left lateral view showing the urethral process.

Table 1. Immunohistochemistry and characterization of equine sarcoid of the glans penis

\begin{tabular}{lllcc}
\hline \multicolumn{1}{c}{ Antibody } & \multicolumn{1}{c}{ Clone } & \multicolumn{1}{c}{ Source } & Dilution & Tumor cells \\
\hline HPV & BPV-1/1 H8 + CAMVIR & Abcam (Cambridge, UK) & $1: 80$ & $\mathrm{~N}$ \\
Cytokeratin AE1/AE3 & AE1, AE3 & Nichirei (Tokyo, Japan) & Prediluted & $\mathrm{N}$ \\
Vimentin & Vim 3B4 & Dako (Glostrup, Denmark) & $1: 100$ & $\mathrm{~S}$ \\
S-100 & Rabbit polyclonal & Nichirei & $1: 50$ & $\mathrm{M}$ \\
Claudin 1 & Rabbit polyclonal & Abcam & $1: 200$ & $\mathrm{M}$ \\
Laminin & Rabbit polyclonal & Abcam & $1: 200$ & $\mathrm{~N}$ \\
Desmin & ZC18 & Nichirei & $1: 50$ & $\mathrm{~N}$ \\
aSMA & 1A4 & Nichirei & Prediluted & $\mathrm{N}$ \\
GFAP & GA5 & Nichirei & Prediluted & $\mathrm{N}$ \\
CD34 & QBEnd 10 & Dako & Prediluted & $\mathrm{N}$ \\
Calponin & CALP & Dako & $1: 50$ & $\mathrm{~N}$ \\
p16 & Rabbit polyclonal & Abcam & $1: 50$ & $\mathrm{~N}$ \\
p53 & DO-7 & Nichirei & Prediluted & W \\
Iba-1 & Rabbit polyclonal & Wako (Osaka, Japan) & $1: 1,000$ & $\mathrm{~N}$ \\
Ki-67 & MIB-1 & Dako & Prediluted & S $(<10 \%)$ \\
\hline
\end{tabular}

HPV, human papillomavirus; BPV, bovine papillomavirus; $\alpha$ SMA, alpha smooth muscle actin; GFAP, glial fibrillary acid protein; Iba-1, ionized calcium-binding adapter molecule 1. Abbreviations for staining intensity: N, negative; S, strong; M, moderate; W, weak. 
evaluated by bootstrap analysis with 1,000 replicates [6]. Pairwise sequence identities were calculated using the CLC Genomics Workbench 7.5.5.

The resected specimen consisted of a large mass of the glans penis (approximately $14 \times 12 \times 10 \mathrm{~cm}$ ). On the cut surfaces, the mass had a whitish fibrotic appearance. The urethral process was partly buried in the mass, and the external urethral orifice was shifted to the left side of the mass (Fig. 2).

Histologically, the overlying stratified squamous (mucosal) epithelium of the glans penis with the urethral process was partly hyperkeratotic and irregularly hyperplastic with long, slender, and anastomosing epithelium (so-called rete pegs or ridges) (Fig. 3). "Picket fence" formation, consists of rows of fibroblasts with perpendicular orientation to the epithelial basement membrane, was absent and no viral inclusions were identified. The remaining overlying epithelium was ulcerated and covered with granulation tissue and suppurative inflammation. The submucosa was expanded by variable amounts of collagen fibers and proliferation of mildly anisocytotic and anisokaryotic fibroblasts arranged in a random, whorled, or crisscross pattern (Fig. 4). The mitotic index of the proliferating fibroblasts was less than one per 10 high-power fields.

Immunohistochemically, there was strong, diffuse cytoplasmic positivity for vimentin, moderate scattered cytoplasmic and nuclear positivity for S-100 (Fig. 5a), and moderate scattered cytoplasmic positivity for claudin 1 in tumor cells (Fig. 5b). Cytokeratin AE1/ AE3, laminin, desmin, alpha-smooth muscle actin, glial fibrillary acid protein, CD34, calponin, and ionized calcium-binding adapter molecule 1 (Iba-1) were negative. Immunolabeling for Iba-1 was observed in macrophages throughout the submucosal tumor. The mucosal epithelium and submucosal tumor cells were negative for the PV antigen and p16; p53 revealed weak, scattered, nuclear positive immunoreactivity in the submucosal tumor cells. The immunohistochemical results are shown in Table 1.

Ultrastructurally, the tumor cells were characterized by various amounts of collagen fibrils and non-cohesive spindle cells. The spindle cells had smooth cell membranes, a single round to deeply indented nucleus, prominent rough endoplasmic reticulum, varying amounts of intermediate filaments, and no myofilaments. They also had thin cytoplasmic processes, and the cell processes were in close contact with those of adjacent cells with gap junctions (Fig. 6). These features are consistent with those described for fibroblasts [11, 17].

PCR was conducted to detect the partial genome of the PV using the MY09-MY11 primer pair. The amplicon was detected in the tissue samples from the glans penis. To amplify the complete genome of the virus, an additional PCR assay was performed using three primer pairs [23]. PCR products were successfully obtained and subjected to next-generation sequencing on the MiSeq platform. The 7945-nucleotide complete genome sequence of the mucosal sarcoid LC549663/Equus caballus/JPN (LC549663) obtained was aligned with sequences of BPV from equine sarcoid and bovine papilloma. Phylogenetic analysis showed that LC549663 branched with Japanese bovine and equine strains and was identified as BPV-1 (Fig. 7). LC549663 was most closely related to Japanese BPV from cutaneous myopericytoma of the abdominal skin of a calf (DDBJ accession no. AB 626705) in Hokkaido, exhibiting 99.96\% nucleotide identity. LC549663 also shared high identity (99.87\%) with Japanese BPV from equine sarcoid (fibropapilloma) (DDBJ accession no. LC510377) on the foreskin of a thoroughbred-cross gelding in Hokkaido [29].

PVs are ubiquitous but highly host species-specific [15]. Affinity of PV for the skin and mucosal epithelium has been considered to be mutually exclusive [4], although recent studies show specific subgroups of PVs could retain a dual tropism [1]. Equine

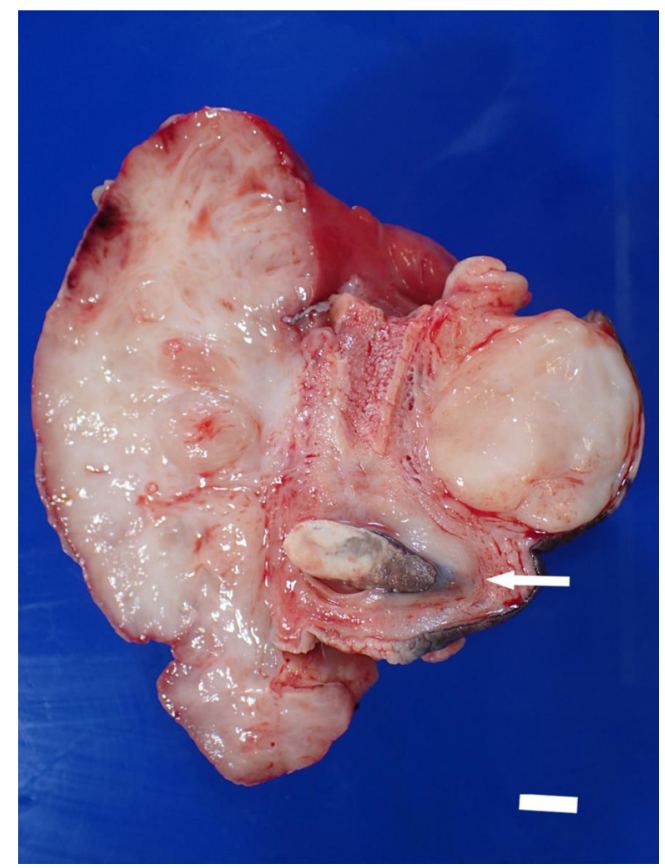

Fig. 2. Coronal section of the mass of the glans penis. The urethral process was partly buried in the mass. External urethral orifice (arrow). Scale bar $=1 \mathrm{~cm}$.

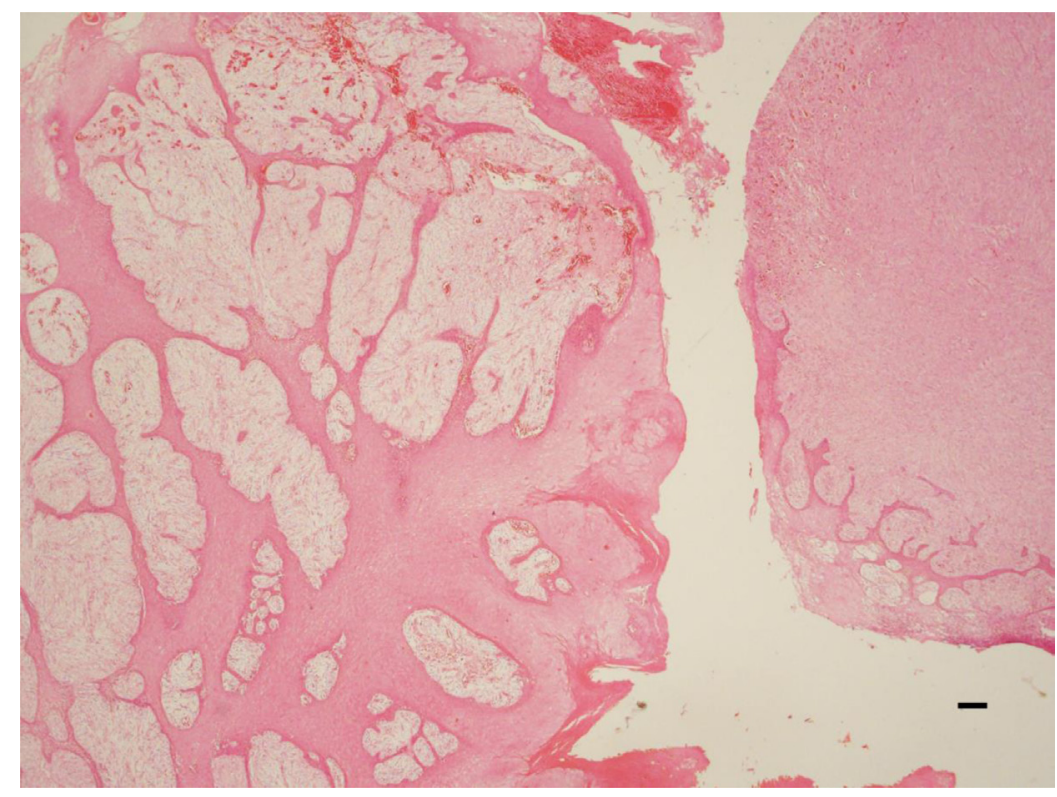

Fig. 3. Coronal section of the urethral process. External urethral orifice. Urinary tract between the wall of the urethral process. Genital and urethral mucosa covered with partly hyperkeratotic and irregularly hyperplastic epithelium with long, slender, and anastomosing rete pegs and granulation tissue. Hematoxylin and eosin (HE) staining. Scale bar $=50 \mu \mathrm{m}$. 


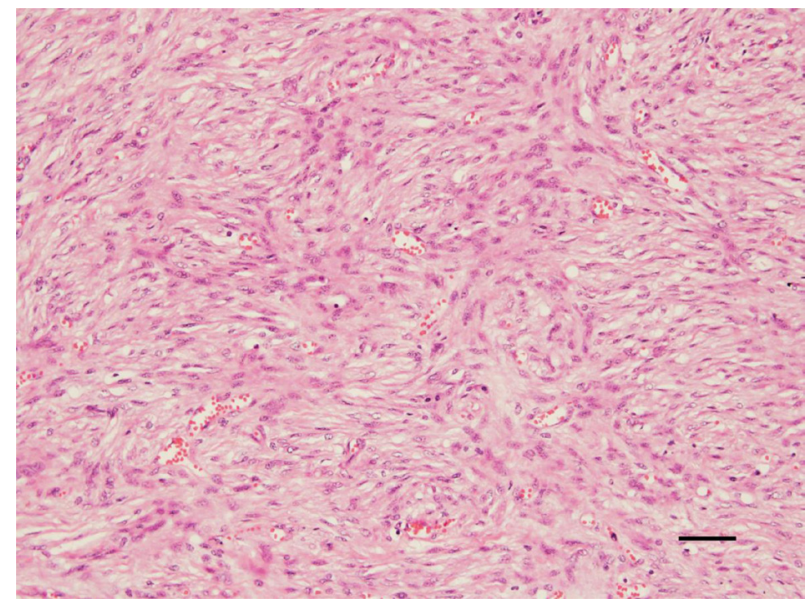

Fig. 4. Urethral submucosa. Mildly anisocytotic and anisokaryotic fibroblasts arranged in a whorled or crisscross pattern. Hematoxylin and eosin (HE) staining. Scale bar $=50 \mu \mathrm{m}$.

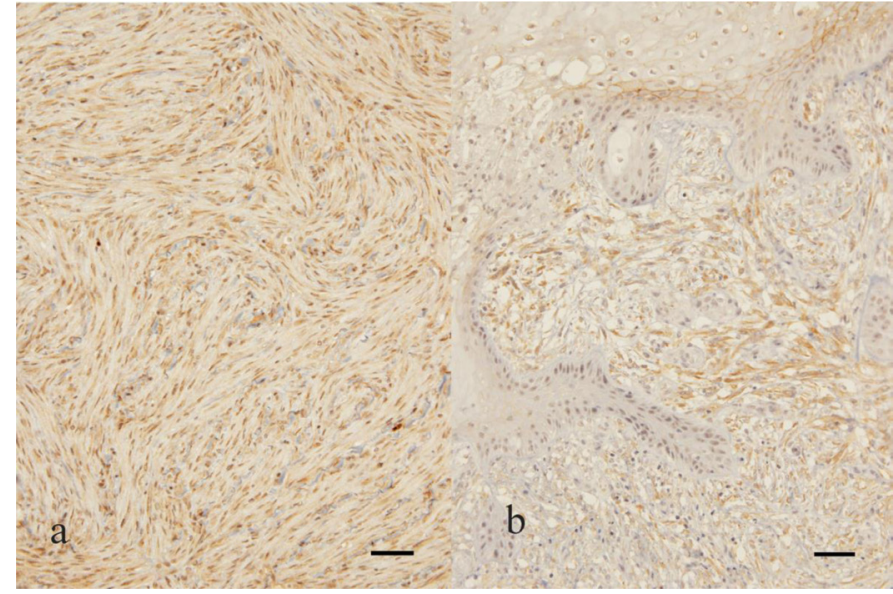

Fig. 5. Immunohistochemistry. Urethral submucosa. a) Moderate, scattered cytoplasmic and nuclear positivity for S-100 in tumor cells. Scale bar $=50 \mu \mathrm{m}$. b) Moderate, scattered cytoplasmic positivity for claudin 1 in tumor cells. Scale bar $=50 \mu \mathrm{m}$.

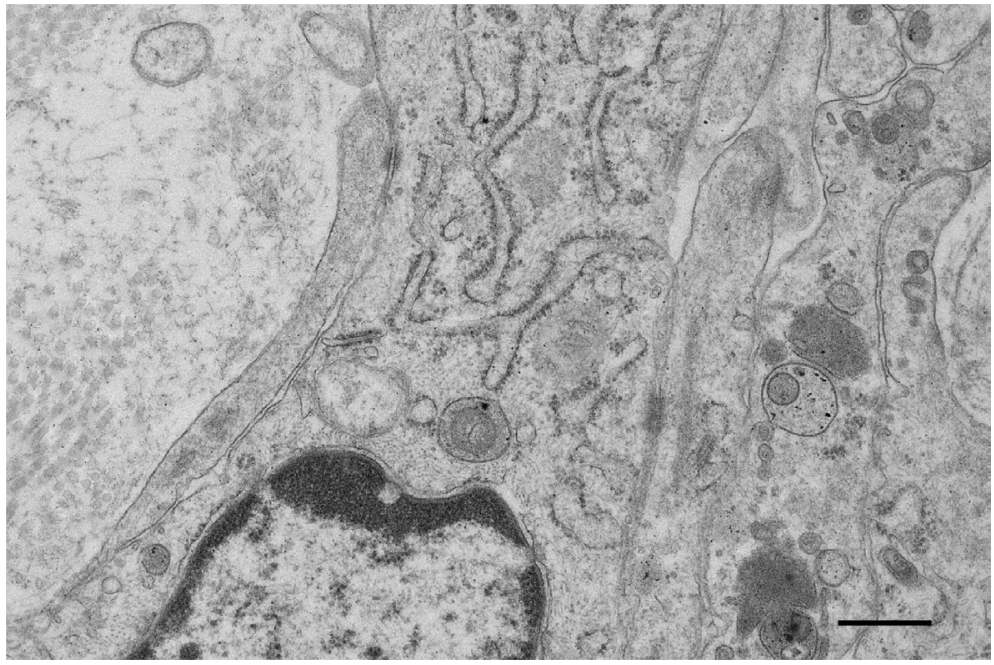

Fig. 6. Transmission electron micrograph. Glans penis submucosa. Collagen fibrils and non-cohesive spindle cells with prominent rough endoplasmic reticulum. Cell processes in close contact with those of adjacent cells with gap junctions. Features of spindle cells consistent with fibroblasts. Scale bar $=1 \mu \mathrm{m}$.

sarcoid is caused by cross-species infection with BPV-1, -2, or -13 and BPV 'BsR-UEL-4' [14, 15, 19] and is the most important and common PV-induced skin tumor affecting horses worldwide, accounting for $35.3-90 \%$ of all skin tumors in the surveys conducted to date $[2,14,21]$.

Equine sarcoid can develop at any skin site on the body but has typical anatomical predilection sites [14, 15, 19, 21], including the head, limbs, ventral abdomen, and paragenital region [2, 21]. Most cases of equine sarcoid on the head develop at the mucocutaneous junction, including the eyelids and commissure of the lips [2, 21], and sarcoid also affect the prepuce with the mucocutaneous junction [22, 26]. To the best of our knowledge, equine sarcoid of the oral and orbital mucosa has not been reported. Only two cases of sarcoid on the penis engulfing the glans penis have been reported in Iran in recent years [10, 20], and fibropapilloma of the glans penis without BPV-1 or BPV-2 DNA has been reported in the US [7]. Equine sarcoid is a cutaneous and mucosal tumor, although the scarcity of published case reports on mucosal sarcoid may reflect its genuine rarity.

Histologically, equine sarcoid was originally considered to be a sarcoma-like mixed (fibroepithelial) tumor [2, 9] but is now categorized as a tumor of soft tissue caused by proliferation of atypical fibroblasts $[8,16,19]$. According to the third edition of the international histologic classification of tumors of soft tissues of domestic animals, a diagnosis of equine sarcoid-affected mucosa of the glans penis and urethral process is confirmed by a combination of histopathology and identification of BPV DNA [19]. There are six clinical forms in equine sarcoid: flat/occult, verrucous, fibroblastic, nodular, mixed, and malignant/"malevolent" [16, 19, 21]. According to clinical categorization by gross appearance [14, 19, 21], the mucosal sarcoid in our case was fibroblastic ("proud flesh-like") sarcoid, as has already been reported to occur in the glans penis [10, 20].

Histopathology is required for a definitive diagnosis of equine sarcoid [14, 21] but may be challenging due to the lack of clear diagnostic criteria [28]. Differentiation of equine sarcoid from other spindle cell tumors or exuberant granulation tissue of the skin 


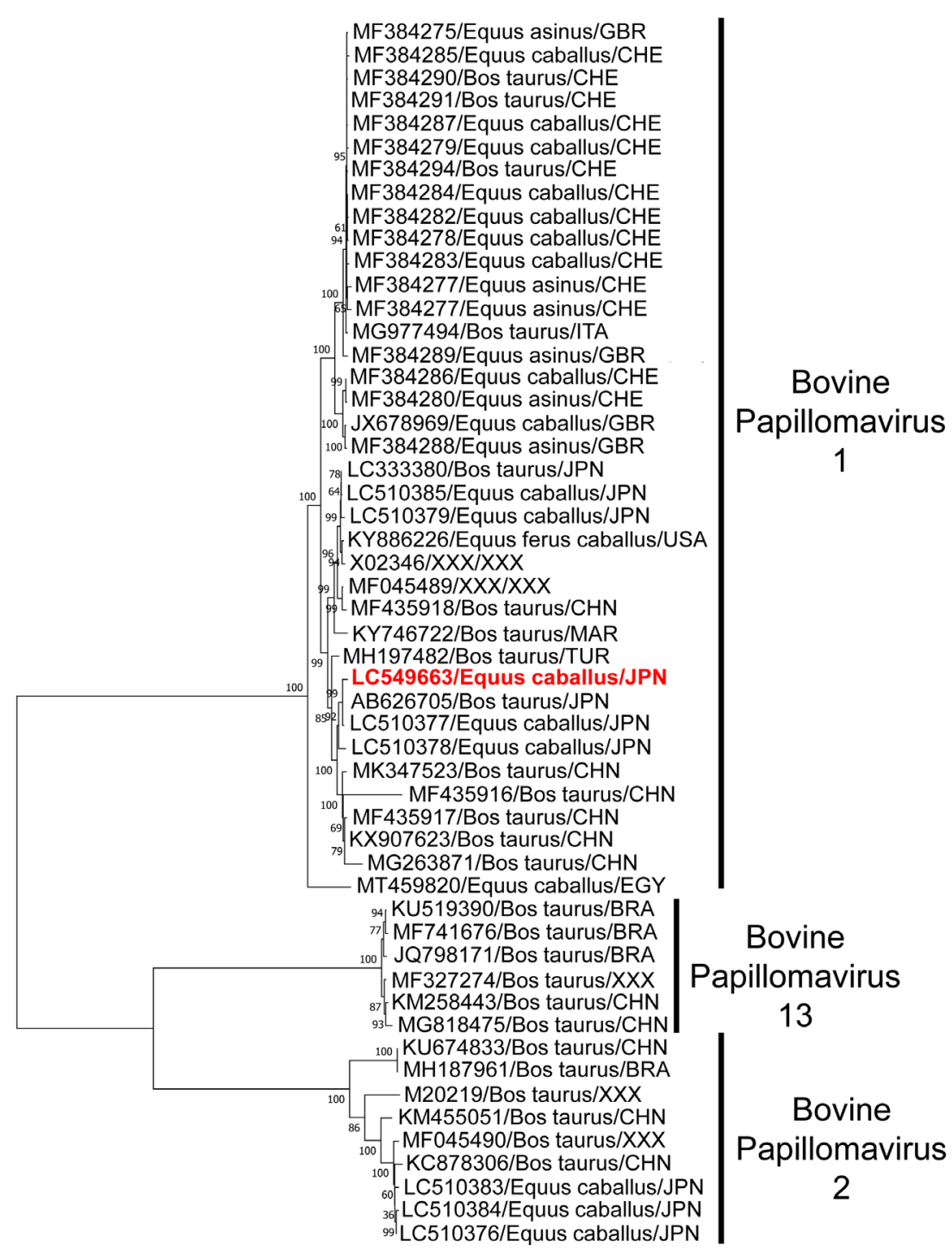

Fig. 7. A phylogenetic tree was constructed using NeighborJoining in MEGA7 with 1,000 bootstrap replicates. The scale bar indicates the corrected genetic distance. LC549663 is indicated in bold red text.

(proud flesh) can be difficult [15, 19, 21].

Furthermore, identification of BPV DNA by PCR is thought to be diagnostic for equine sarcoid [3, 8], although BPV DNA can be demonstrated in $70 \%$ of equine sarcoids and in equine spindle cell tumors in the skin other than equine sarcoid by BPV PCR in paraffin-embedded tissues [5]. The mere presence of BPV DNA is of limited value in the diagnosis of equine sarcoid [16, 28].

Immunohistochemistry for equine sarcoid often requires additional diagnostic tests and differentiation from other spindle cell tumors of the skin but may not be conclusive. Equine sarcoid cells are vimentin-positive and may be laminin-positive, SMA-positive [3] and S100 positive [5]. The mucosal sarcoid in our case showed positive immunoreactivity for vimentin and S-100 and negative immunoreactivity for laminin and SMA. There was scattered cytoplasmic positivity for claudin 1. Claudin 1 is a tight junction-related protein [18] and is not a marker of perineural cells in equine tissue [27]. In the human medical literature, claudin-1 is reportedly expressed in perineurioma-like lowgrade fibromyxoid sarcoma [25]. Claudin-1 also induces epithelial-mesenchymal transition [24]. In our case of equine sarcoid, PV and p16 immunohistochemistry studies revealed no immunoreactivity in the mucous epithelium or submucosal tumor cells. Immunohistochemical detection of the presence of BPV virus late proteins failed, and the BPV production in horses remains questionable in equine sarcoid [16].

Clinically, equine sarcoid is a progressive disease that invades and destroys the surrounding tissue and recurs frequently following surgical excision [19,21]. Equine sarcoid is not lethal, but functional impairment may necessitate euthanasia or slaughter [2]. Equine sarcoid becomes a dangerous problem when the glans penis is involved and causes dysuria [10], as in our case.

Genomic studies of BPV in equine sarcoid have been reported worldwide, including in Japan [29]. Phylogenetic analysis of LC549663 revealed high sequence homology to BPVs derived from cutaneous myopericytoma of a calf and from equine sarcoid of a horse kept in Hokkaido, Japan, suggesting a geographical relationship of BPV-1 in Japan [29]. In this case, the old Falabella gelding may have been infected with BPV-1 local to Japan. Domestic transport of horses and cattle may explain the relationship between BPV-1, horses, and cattle in Japan. 
In conclusion, equine sarcoid of the glans penis is a genital and urethral mucosal disease associated with cross-species BPV-1 infection and may cause functional impairment. Phylogenetic analysis of the BPV-1 genome in our case suggested a geographical relationship between BPV-1 in horses and cattle in Japan. This report will contribute to further understanding of the pathology and geographical epidemiology of mucosal sarcoid in horses.

CONFLICT OF INTEREST. The authors declare no conflicts of interest regarding the publication of this manuscript.

ACKNOWLEDGMENTS. The authors thank Ms. Kanako Satoh and Ms. Megumi Mori for their expert technical assistance.

\section{REFERENCES}

1. Altamura, G., Tommasino, M. and Borzacchiello, G. 2020. Cutaneous vs. mucosal tropism: the papillomavirus paradigm comes to an "and". Front. Microbiol. 11: 588663. [Medline] [CrossRef]

2. Bogaert, L., Martens, A., Depoorter, P. and Gasthuys, F. 2008. Equine sarcoids-part 1: clinical presentation and epidemiology. Vlaams Diergeneeskd. Tijdschr. 77: 2-9.

3. Bogaert, L., Heerden, M. V., De Cock, H. E. V., Martens, A. and Chiers, K. 2011. Molecular and immunohistochemical distinction of equine sarcoid from schwannoma. Vet. Pathol. 48: 737-741. [Medline] [CrossRef]

4. de Villiers, E. M. 2013. Cross-roads in the classification of papillomaviruses. Virology 445: 2-10. [Medline] [CrossRef]

5. Epperson, E. D. and Castleman, W. L. 2017. Bovine papillomavirus DNA and S100 profiles in sarcoids and other cutaneous spindle cell tumors in horses. Vet. Pathol. 54: 44-52. [Medline] [CrossRef]

6. Felsenstein, J. 1985. Confidence limits on phylogenies: an approach using the bootstrap. Evolution 39: 783-791. [Medline] [CrossRef]

7. Gardiner, D. W., Teifke, J. P., Podell, B. K. and Kamstock, D. A. 2008. Fibropapilloma of the glans penis in a horse. J. Vet. Diagn. Invest. 20: 816-819. [Medline] [CrossRef]

8. Hendrick, M. J. 2017. Mesenchymal tumors of the skin and soft tissues. pp. 142-175. In: Tumors in Domestic Animals, 5th ed. (Meuten, D. J. ed.), John Wiley \& Sons, Ames.

9. Jackson, C. 1936. The incidence and pathology of tumors of domesticated animals in South Africa. Onderstepoort. J. Vet. Sci. Anim. Indust. 6: 378-385.

10. Kish, G. F., Nazhvani, S. D., Namazi, F. and Jalali, Y. 2014. Penile sarcoid in horse: clinicopathological characteristics with brief literature review. Comp. Clin. Pathol. 23: 459-462. [CrossRef]

11. Ko, K., Arora, P., Lee, W. and McCulloch, C. 2000. Biochemical and functional characterization of intercellular adhesion and gap junctions in fibroblasts. Am. J. Physiol. Cell Physiol. 279: C147-C157. [Medline] [CrossRef]

12. Kumar, S., Stecher, G. and Tamura, K. 2016. MEGA7: Molecular evolutionary genetics analysis version 7.0 for bigger datasets. Mol. Biol. Evol. 33: 1870-1874. [Medline] [CrossRef]

13. Manos, M. M., Ting, Y., Wright, D. K., Lewis, A. I., Broker, T. R. and Wolinsky, S. M. 1989. The use of polymerase chain reaction amplification for the detection of genital human papillomaviruses. Cancer Cells 7: 209-214.

14. Mauldin, E. A. and Peters-Kennedy, J. 2016. Papilloma and papillomavirus-induced lesions. pp. 706-712. In: Jubb, Kennedy and Palmer's Pathology of Domestic Animals (Volume 1), 6th ed. (Maxie, M. G. ed.), Elsevier Science, St. Louis.

15. Munday, J. and Pesavento, P. 2017. Chapter 11 Papillomaviridae and Polyomaviridae. pp. 229-243. In: Fenner's Veterinary Virology, 5th ed. (MacLachlan, N. J. and Dubovi, E. J. eds.), Academic Press, Cambridge.

16. Ogłuszka, M., Starzyński, R. R., Pierzchała, M., Otrocka-Domagała, I. and Raś, A. 2021. Equine sarcoids—causes, molecular changes, and clinicopathologic features: a review. Vet. Pathol. 58: 472-482. [Medline] [CrossRef]

17. Oyamada, T., Akachi, S., Yoshikawa, H. and Yoshikawa, T. 1991. Pathological studies on equine sarcoid in Japan. Pathological findings of 31 cases. Jpn. J. Equine Sci. 2: 31-39. [CrossRef]

18. Paschoud, S., Bongiovanni, M., Pache, J. C. and Citi, S. 2007. Claudin-1 and claudin-5 expression patterns differentiate lung squamous cell carcinomas from adenocarcinomas. Mod. Pathol. 20: 947-954. [Medline] [CrossRef]

19. Roccabianca, P., Schulman, F. Y., Avallone, G., Foster, R. A., Scruggs, J. L., Dittmer, K. and Kiupel, M. 2020. Equine sarcoid. pp. 91-97. In: Surgical Pathology of Tumors of Domestic Animals, Volume 3, Tumors of Soft Tissue (Kiupel, M. ed.), Davis-Thompson Foundation, Grunee.

20. Saadi, A., Azizi, S., Farshid, A. A. and Yousefi, A. 2019. Surgical management of penile sarcoid in a stallion. J. Equine Sci. 30: 99-104. [Medline] [CrossRef]

21. Scott, D. W. and Miller, W. H. Jr. 2011. Sarcoid. pp. 479-488. In: Equine Dermatology, 2nd ed., Elsevier Science, St. Louis.

22. Scott, V. H. L. and Hughes, K. 2017. Diagnosis of equine penile and preputial masses: a clinical and pathological perspective. Equine Vet. Educ. 29: 10-14. [CrossRef]

23. Shimakura, H., Dong, J., Zhu, W., Chambers, J. K., Uchida, K., Kiriki, K., Uematsu, M., Goto, Y., Yasuda, M., Yamashita-Kawanishi, N., Tsuzuki, M., Le, D. T., Hatama, S. and Haga, T. 2018. Full genome analysis of bovine papillomavirus type 1 derived from a calf with severe cutaneous multiple papillomatosis. J. Vet. Med. Sci. 80: 1691-1695. [Medline] [CrossRef]

24. Suh, Y., Yoon, C. H., Kim, R. K., Lim, E. J., Oh, Y. S., Hwang, S. G., An, S., Yoon, G., Gye, M. C., Yi, J. M., Kim, M. J. and Lee, S. J. 2013. Claudin-1 induces epithelial-mesenchymal transition through activation of the c-Abl-ERK signaling pathway in human liver cells. Oncogene 32: 4873-4882. [Medline] [CrossRef]

25. Thway, K., Fisher, C., Debiec-Rychter, M. and Calonje, E. 2009. Claudin-1 is expressed in perineurioma-like low-grade fibromyxoid sarcoma. Hum. Pathol. 40: 1586-1590. [Medline] [CrossRef]

26. Van Den Top, J. G. B., Ensink, J. M., Gröne, A., Klein, W. R., Barneveld, A. and Van Weeren, P. R. 2010. Penile and preputial tumours in the horse: literature review and proposal of a standardised approach. Equine Vet. J. 42: 746-757. [Medline] [CrossRef]

27. Vashisht, K., Rock, R. W. and Summers, B. A. 2007. Multiple masses in a horse's tongue resulting from an atypical perineurial cell proliferative disorder. Vet. Pathol. 44: 398-402. [Medline] [CrossRef]

28. Wobeser, B. K. 2017. Making the diagnosis. Vet. Pathol. 54: 9-10. [Medline] [CrossRef]

29. Yamashita-Kawanishi, N., Chambers, J. K., Uchida, K., Tobari, Y., Yoshimura, H., Yamamoto, M., Yumoto, N., Aoki, H., Sugiura, K., Higuchi, T., Saito, S. and Haga, T. 2020. Genomic characterisation of bovine papillomavirus types 1 and 2 identified in equine sarcoids in Japan. Equine Vet. J. 10.1111/evj.13398. [Medline] 